\title{
Non-invasive assessment of diastolic function in hypertrophic cardiomyopathy on and off beta adrenergic blocking drugs
}

\author{
R F ALVARES, J F GOODWIN \\ From the Division of Cardiovascular Disease, Royal Postgraduate Medical School, Hammersmith Hospital, London
}

SUMMARY Beta adrenergic blocking drugs in hypertrophic cardiomyopathy provide symptomatic relief but their effect on long-term prognosis is uncertain.

Thirty patients were studied non-invasively by simultaneous recordings of echocardiogram, apexcardiogram, phonocardiogram, and electrocardiogram in order to assess diastolic abnormalities on and off oral beta adrenergic blocking drugs. While on treatment these patients had a mean dose of propranolol $200 \mathrm{mg} /$ day. The treatment was stopped for one week and then non-invasive assessment was repeated.

The following diastolic time intervals were studied: isovolumic relaxation period $\left(\mathbf{A}_{2}-\right.$ mitral valve opening); rapid relaxation period $\left(\mathrm{A}_{2}-\mathrm{O}\right.$ point of the apexcardiogram), and the period from mitral valve opening to the $\mathrm{O}$ point of the apexcardiogram (Mo-O) when most of the filling of the left ventricle occurs. The prolongation of the rapid relaxation period reflects a reduced rate of fall of the left ventricular pressure when the pressure differential does not change between $A_{2}$ and the $O$ point of the apexcardiogram, and in this study this period was prolonged in 19, shortened in eight, and remained the same in three patients after beta blockade. The Mo-O point was prolonged in 22, shortened in seven, and was unchanged in one patient after beta adrenergic blocking drugs. All these results were independent of heart rate.

In conclusion the response of diastolic time intervals to beta blocking drugs in hypertrophic cardiomyopathy was variable but there was a significant number of patients in whom the time available for filling of the left ventricle was prolonged, suggesting better filling possibly because of improved distensibility of the left ventricle after beta adrenergic blocking drugs.

For the past two decades beta adrenergic blocking drugs have been widely used in the treatment of hypertrophic cardiomyopathy and since early trials they have been shown to produce important symptomatic benefits. ${ }^{1-3} \mathrm{~A}$ double blind trial of practolol, propranolol, and a placebo has suggested that beta blockade was associated with amelioration or disappearance of dyspnoea, anginal pain, and syncope in severely symptomatic patients ${ }^{4}$ but unfortunately beta adrenergic blockade cannot be guaranteed to prevent sudden death. ${ }^{56}$

Hypertrophic cardiomyopathy is a disease characterised by massive hypertrophy and impaired distensibility of the left ventricle which leads to abnormal

Accepted for publication 25 March 1982 diastolic filling with a small systolic cavity and a very stiff ventricle. ${ }^{7-9}$

We believe that this abnormal diastolic filling is the most important factor in determining symptoms and prognosis regardless of whether a gradient between the outflow tract of the left ventricle and aorta is present or not.

It has been known that beta adrenergic stimulation increases the pressure gradient between left ventricle and aorta and decreases the calculated orifice size of the outflow tract of the left ventricle. Such stimulation may be produced or be augmented by exercise, tachycardia, emotion, and drugs that have a positive inotropic effect. ${ }^{1011}$

Therefore it was thought initially that this improvement of symptomatology was the result of a decreased pressure gradient across the outflow tract 
with a lower cardiac output, in proportion to the decrease in heart rate, 12 but subsequent workers have shown by invasive ${ }^{1314}$ and non-invasive ${ }^{4} 615$ methods that the important mechanism of action of beta blockade was an increase in left ventricular distensibility, allowing the inflow of an increased volume of blood during diastole.

One of the difficulties in interpreting the value of these drugs has been the lack of objective assessment of the results of oral treatment.

Therefore in the present study an attempt was made to study filling and relaxation, the two main interdependent events in early diastole, in hypertrophic cardiomyopathy on and off oral beta adrenergic blocking drugs, in order to detect any important changes after beta blockade.

We have studied the events during diastole using simultaneous non-invasive recordings of the left ventricle and mitral valve echocardiogram, apexcardiogram, phonocardiogram, and electrocardiogram. ${ }^{16}$

\section{Subjects and methods}

Observations were made on 30 patients who fulfilled the clinical, ${ }^{7}$ electrocardiographic, ${ }^{17}$ echocardiographic, 1819 and angiographic criteria for hypertrophic cardiomyopathy. All these patients were in attendance at Hammersmith Hospital and their clinical details are given in Table 1. The group included eight women and 22 men with a mean age of 44 years (range from 14 to 63 years). Twenty-four patients were in sinus rhythm and six in atrial fibrillation. Twelve patients had a left venticular outflow tract gradient at rest, seven had a gradient only on provocation, and 11 patients had no demonstrable gradient. None of these 30 patients was in cardiac failure.

Of these 30 patients, propranolol (mean dose of 230 $\mathrm{mg} /$ day) was being taken by 20 patients; oxprenolol and metoprolol were being taken by five patients each in a mean dosage of $252 \mathrm{mg}$ and $130 \mathrm{mg} /$ day, respectively. The latter drugs were used because of intolerance to propranolol. All these patients were on beta adrenergic blocking drugs for at least one month (when initially studied with non-invasive techniques). The treatment was then stopped for one week and the non-invasive assessment was repeated.

These 30 patients were studied with simultaneous recordings of apexcardiogram, left ventricular and mitral valve echocardiogram, phonocardiogram, and electrocardiogram (Fig. 1).

The subjects lay comfortably in the left lateral recumbent position in the moveable angiography cradle with their head and shoulders raised $\left(15-20^{\circ}\right)$. The left arm was raised so that the apex beat could be easily located. The right arm rested along the right side and the cradle was rotated between 30 and $60^{\circ}$ to the left in order to ensure the best quality of the apexcardiograms and echocardiograms. Measurements

Table 1 Clinical details of 30 patients studied on and off beta blocking drugs

\begin{tabular}{|c|c|c|c|c|c|c|c|c|}
\hline Case No. & Age & Sex & Rhythm & $\begin{array}{l}\text { Heart rate } \\
\text { (beats/min) }\end{array}$ & $\begin{array}{l}\text { Gradient } \\
\text { at rest }\end{array}$ & $\begin{array}{l}\text { Gradient on } \\
\text { provocation }\end{array}$ & Drug & $\begin{array}{l}\text { Dosage } \\
\text { (mg/day) }\end{array}$ \\
\hline $\begin{array}{r}1 \\
2 \\
3 \\
4 \\
5 \\
6 \\
7 \\
8 \\
9 \\
10 \\
11 \\
12 \\
13 \\
14 \\
15 \\
16 \\
17 \\
18 \\
19 \\
20 \\
21 \\
22 \\
23 \\
24 \\
25 \\
26 \\
27 \\
28 \\
29 \\
30\end{array}$ & $\begin{array}{l}60 \\
36 \\
42 \\
32 \\
48 \\
32 \\
41 \\
37 \\
38 \\
46 \\
55 \\
46 \\
44 \\
43 \\
51 \\
30 \\
58 \\
57 \\
57 \\
44 \\
14 \\
48 \\
38 \\
31 \\
34 \\
57 \\
17 \\
63 \\
56 \\
58\end{array}$ & $\begin{array}{l}\mathbf{M} \\
\mathbf{M} \\
\mathbf{M} \\
\mathbf{M} \\
\mathbf{M} \\
\mathbf{F} \\
\mathbf{M} \\
\mathbf{M} \\
\mathbf{F} \\
\mathbf{F} \\
\mathbf{M} \\
\mathbf{M} \\
\mathbf{M} \\
\mathbf{M} \\
\mathbf{M} \\
\mathbf{M} \\
\mathbf{F} \\
\mathbf{M} \\
\mathbf{M} \\
\mathbf{M} \\
\mathbf{M} \\
\mathbf{M} \\
\mathbf{F} \\
\mathbf{F} \\
\mathbf{M} \\
\mathbf{M} \\
\mathbf{M} \\
\mathbf{F} \\
\mathbf{F} \\
\mathbf{M}\end{array}$ & $\begin{array}{l}\text { SR } \\
\text { SR } \\
\text { SR } \\
\text { SR } \\
\text { SR } \\
\text { SR } \\
\text { SR } \\
\text { SR } \\
\text { SR } \\
\text { SR } \\
\text { SR } \\
\text { SR } \\
\text { SR } \\
\text { SR } \\
\text { AF } \\
\text { AF } \\
\text { AF } \\
\text { AF } \\
\text { AF } \\
\text { AF } \\
\text { SR } \\
\text { SR } \\
\text { SR } \\
\text { SR } \\
\text { SR } \\
\text { SR } \\
\text { SR } \\
\text { SR } \\
\text { SR } \\
\text { SR }\end{array}$ & $\begin{array}{r}56 \\
81 \\
74 \\
58 \\
61 \\
53 \\
72 \\
63 \\
69 \\
48 \\
56 \\
65 \\
66 \\
66 \\
86 \\
79 \\
84 \\
130 \\
110 \\
83 \\
76 \\
67 \\
69 \\
74 \\
55 \\
73 \\
70 \\
71 \\
77 \\
56\end{array}$ & $\begin{array}{l}+ \\
+ \\
- \\
- \\
- \\
- \\
- \\
+ \\
+ \\
- \\
+ \\
- \\
- \\
- \\
+ \\
- \\
+ \\
- \\
+ \\
+ \\
- \\
+ \\
+ \\
+ \\
+ \\
-\end{array}$ & $\begin{array}{l}+ \\
+ \\
- \\
+ \\
- \\
- \\
- \\
+ \\
+ \\
+ \\
+ \\
+ \\
- \\
- \\
- \\
+ \\
+ \\
+ \\
+ \\
+ \\
+ \\
+ \\
+ \\
+ \\
+ \\
+ \\
+ \\
+ \\
+ \\
+\end{array}$ & 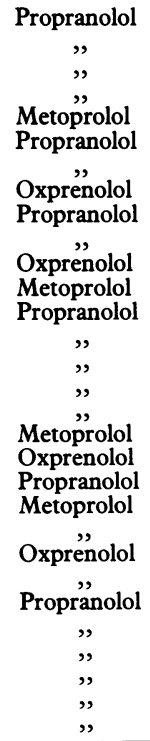 & $\begin{array}{r}120 \\
800 \\
80 \\
240 \\
100 \\
30 \\
120 \\
240 \\
60 \\
120 \\
240 \\
200 \\
80 \\
240 \\
240 \\
480 \\
240 \\
100 \\
240 \\
720 \\
50 \\
200 \\
480 \\
60 \\
240 \\
200 \\
120 \\
120 \\
240 \\
120 \\
\end{array}$ \\
\hline
\end{tabular}




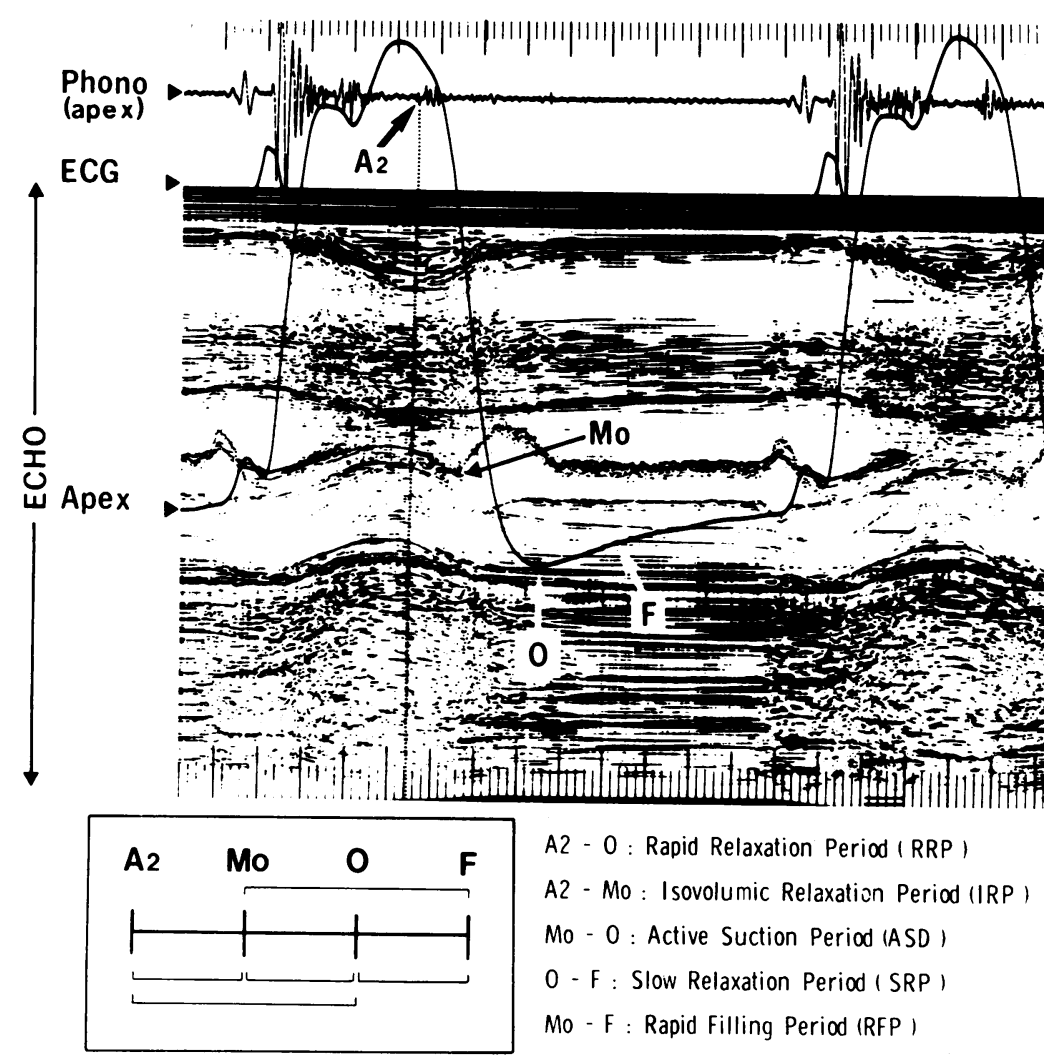

Fig. 1 Simultaneous recording of phonocardiogram (phono), electrocardiogram (ECG), apexcardiogram (apex), and echocardiogram (echo) in a patient with hypertrophic candiomyopathy. Diagram shows the diastolic time intervals measured. A2, aortic component of second heart sound; Mo, mitral valve opening. $O$ and $F$ points of the apexcardiogram.

were made only on technically satisfactory recordings.

The equipment used was the model VR-12 simultrace system (Electronics for Medicine). This is a multichannel physiological recording system designed for high resolution recording of a variety of signals, including echocardiograms. The photographic tracings were recorded during relaxed expiratory apnoea at a paper speed of $100 \mathrm{~mm}$ per second with 0.02 second time lines. This allows a maximal attainable limit for measuring diastolic time intervals of $5 \mathrm{~ms}$. Since the timing of different events during diastole was measured this method is reproducible. ${ }^{20}$

\section{APEXCARDIOGRAM AND PHONOCARDIOGRAM}

The apexcardiogram and phonocardiogram (from the apex) were obtained from a single $E$ for $M$ model PSA-23 crystal transducer with infinite time constant. It was positioned at the point where the apexcardiogram was similar to the left ventricular pressure curve and usually coincided with the point of maximal car- diac impulse. The transducer was held in place by an adjustable elastic strap. The model V-2207 phonocardiograph amplifier permitted separate frequencyselective amplification and display of the apexcardiogram with a frequency response of 0.1 to $30 \mathrm{~Hz}$ and the phonocardiogram with a band of interest of 50 to 1000 $\mathrm{Hz}$. In this fashion the apexcardiogram was recorded simultaneously with the phonocardiogram from the same site.

During the examination of each patient a second phonocardiogram was obtained from the base of the heart using a second crystal transducer simultaneously with the carotid pulse in order to define accurately the aortic component of the second heart sound.

\section{ECHOCARDIOGRAM}

The echocardiogram was obtained simultaneously with the apexcardiogram, phonocardiogram, and electrocardiogram using the $\mathrm{E}$ for $\mathrm{M}$ model V-3280 mod- 
ule and a $1.25 \mathrm{~cm}$ diameter, $2.25 \mathrm{MHz}$ transducer. The system provided a pulse repetition rate of 1000 cycles per second, multilevel gain compensation in either continuous time mode, or discrete depth mode with independent adjustments every $2 \mathrm{~cm}$ over $24 \mathrm{~cm}$ range. Echoes were obtained simultaneously from the interventricular septum, posterior wall, and both the leaflets of the mitral valve paying special attention to the point where the anterior and posterior leaflets separate. During examination gain settings were continuously adjusted with a foot switch until the best available recordings could be made.

From these traces the following variables were measured and are summarised in Fig. 1: (1) heart rate; (2) rapid relaxation period-interval from aortic valve closure $\left(\mathrm{A}_{2}\right)$ to the $\mathrm{O}$ point of the apexcardiogram; (3) isovolumic relaxation period-interval from $A_{2}$ to mitral valve opening (Mo) defined as the point where both the leaflets of the mitral valve separate on the echocardiogram; (4) active suction periodinterval from Mo to the $\mathrm{O}$ point of the apexcardiogram; (5) rapid filling period-interval from Mo to the $F$ point of the apexcardiogram.

The measurements of timing of different events during diastole were made in milliseconds, from a mean of at least 20 cycles, except for digitising data where two cycles were used; the measurements of dimensions were in centimetres and the velocity in centimetres per second. The results were given as those lying within the range of one standard deviation of the corresponding mean value. The statistical significance of differences between means of normally distributed populations was assessed by Student's $t$ test.

\section{Results}

(1) Heart rate: the mean heart rate of patients off treatment was $71.6 \pm 16.6$ beats per minute. Fig. 2 shows that the heart rate decreased significantly after beta blockade in all but four patients. The mean heart rate on beta blockade was $58.1 \pm 10.9$ beats per minute $(\mathrm{p}<0.001)$.

(2) Rapid relaxation period: $A_{2}-O$. The mean rapid relaxation period for all patients was prolonged after beta blockade from $178.0 \pm 42.9$ to $185.0 \pm 47.7 \mathrm{~ms}$ (Table 2). Though overall there was an increase of rapid relaxation period reflecting prolonged relaxation after beta blockade, this was not significant ( $p>0.15)$. As shown in Fig. 3, however, in 19 patients there was a prolongation of rapid relaxation period, in eight patients it was shortened, and it remained unchanged in three.

(3) Isovolumic relaxation period: $A_{2}-M o$. Overall the isovolumic relaxation period was shortened in patients with hypertrophic cardiomyopathy after beta

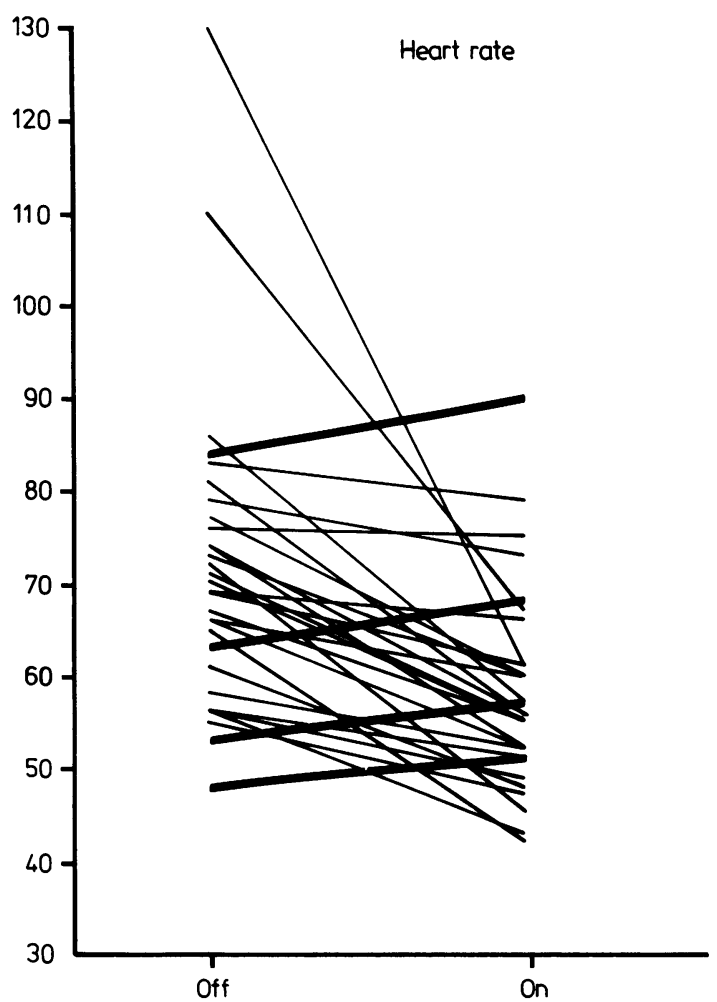

Fig. 2 The heart rate off and on beta adrenergic blocking drugs. Thin and thick lines represent patients in whom the heart rate decreased and increased, respectively, on beta blockade.

adrenergic blocking drugs but this change was also not significant. The mean value off beta blockade was $82.8 \pm 27.9 \mathrm{~ms}$ which decreased after treatment to $77.0 \pm 28.0 \mathrm{~ms}(p>0 \cdot 10)$. From the whole group the isovolumic relaxation period, however, was shortened in 16, prolonged in 12, and remained the same in two (Fig. 4 and Table 2).

(4) Active suction period: Mo-O. In contrast to rapid relaxation period and isovolumic relaxation period, the mean active suction period was significantly prolonged after treatment when the whole group was considered. The increase was from $95 \cdot 1 \pm 31 \cdot 3$ to $108.1 \pm 41.0 \mathrm{~ms}(p<0.01)$ as shown in Table 2 and Fig. 5. From the whole group, this interval was prolonged in 22 , was shortened in seven, and remained the same in one patient.

From the group of 22 patients who had prolongation of the active suction period after beta blockade, 11 had shortening of the isovolumic relaxation period after treatment, nine had prolongation, and two had no change.

(5) Rapidfilling period: $M o-F$. Overall the rapid filling period was significantly prolonged in patients after beta adrenergic blocking drugs $(169.7 \pm 31.0$ to 
Table 2 Behaviour of diastolic time intervals on and off beta blockade in hypertrophic cardiomyopathy

\begin{tabular}{|c|c|c|c|c|c|c|}
\hline & Off (ms) & $O n(m s)$ & $P$ values & & Off (ms) & $O n(m s)$ \\
\hline $\begin{array}{l}\text { Rapid relaxation } \\
\text { period }\left(\mathrm{A}_{2}-\mathrm{O}\right)\end{array}$ & $178 \cdot 0 \pm 42 \cdot 9$ & $195 \cdot 0 \pm 47 \cdot 7$ & $\mathbf{p}<0.15$ & $\begin{array}{l}19 \text { prolonged } \\
8 \text { shortened } \\
3 \text { same }\end{array}$ & $\begin{array}{l}168.9 \pm 41 \cdot 3 \\
196.8 \pm 47.8 \\
185.0 \pm 32.7\end{array}$ & $\begin{array}{l}196.0 \pm 50.7 \\
158.7 \pm 37 \cdot 3 \\
185.0 \pm 32.7\end{array}$ \\
\hline $\begin{array}{l}\text { Isovolumic relaxation } \\
\text { period }\left(\mathrm{A}_{2}-\mathrm{Mo}_{0}\right)\end{array}$ & $82.8 \pm 27.9$ & $77 \cdot 0 \pm 28 \cdot 0$ & $\mathrm{p}<0.10$ & $\begin{array}{l}12 \text { prolonged } \\
16 \text { shortened } \\
2 \text { same }\end{array}$ & $\begin{array}{l}81.2 \pm 24.2 \\
86.8 \pm 31.4 \\
60.0 \pm\end{array}$ & $\begin{array}{l}99.5 \pm 23.1 \\
62 \cdot 1 \pm 21 \cdot 2 \\
60.0 \pm\end{array}$ \\
\hline $\begin{array}{l}\text { Active suction } \\
\text { period }\left(M_{0}-0\right)\end{array}$ & $95 \cdot 1 \pm 31 \cdot 3$ & $108 \cdot 1 \pm 41 \cdot 0$ & $\mathrm{p}<0.01$ & $\begin{aligned} & 22 \text { prolonged } \\
& 7 \text { shortened } \\
&\end{aligned}$ & $\begin{array}{r}90.6 \pm 31 \cdot 1 \\
112.1 \pm 29.5 \\
72.9 \pm\end{array}$ & $\begin{array}{r}115.6 \pm 43.4 \\
89.2 \pm 26.8 \\
72.9 \pm\end{array}$ \\
\hline $\begin{array}{l}\text { Rapid filling } \\
\text { period (Mo-E) }\end{array}$ & $169 \cdot 6 \pm 31 \cdot 0$ & $193 \cdot 5 \pm 47 \cdot 1$ & $p<0.0005$ & $\begin{array}{l}22 \text { prolonged } \\
6 \text { shortened } \\
2 \text { same }\end{array}$ & $\begin{array}{l}172.5 \pm 33.9 \\
160.8 \pm 24.7 \\
165.0 \pm 7.0\end{array}$ & $\begin{array}{l}209.7 \pm 43.0 \\
143 \cdot 3 \pm 24 \cdot 6 \\
165 \cdot 0 \pm 7 \cdot 0\end{array}$ \\
\hline
\end{tabular}

*p values calculated by Student's $t$ test.

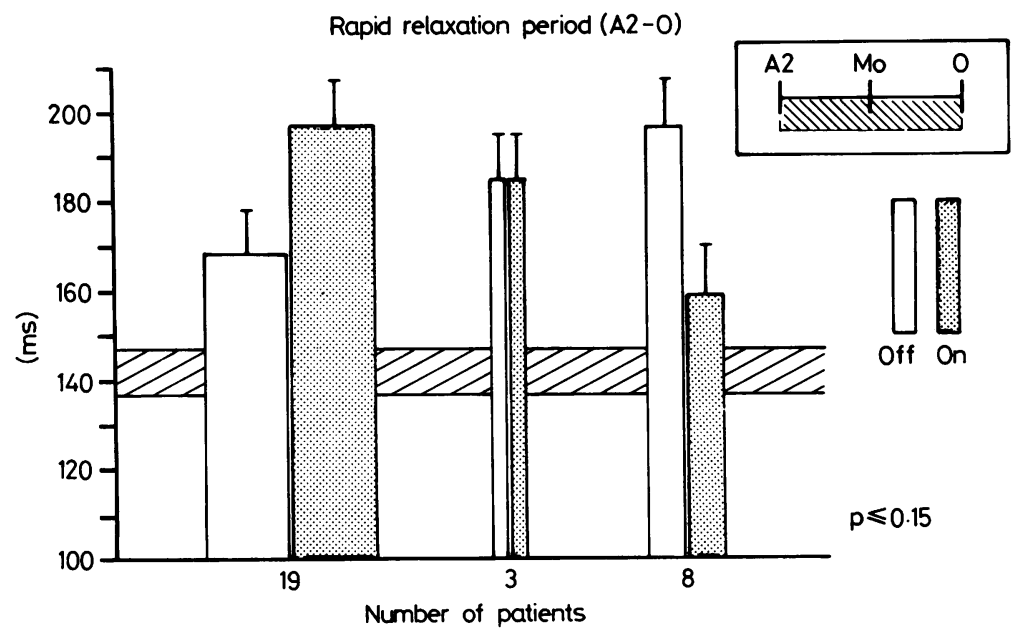

Fig. 3 Histograms showing the effect of beta blockade on rapid relaxation period (mean $\pm S D$ ) off treatment (white histograms) and on treatment (stippled histograms). The horizontal bar represents the normal mean value $\pm S D$ in normal subjects off beta adrenergic blocking drugs.

$193.5 \pm 47.1 \mathrm{~ms}, \mathrm{p}<0.0005)$. From these 30 patients, in 22 the rapid filling period increased after treatment, in six it was shortened, and in two it remained unchanged (Table 2).

\section{Discussion}

The investigation of diastole using simultaneous noninvasive methods such as phonocardiogram, electrocardiogram, left ventricular echocardiogram, and apexcardiogram is possibly at the moment the most effective way to study the events during diastole.

It is possible to identify three important landmarks during the early diastolic period using these techniques: aortic valve closure $\left(A_{2}\right)$, mitral valve opening (Mo), and the $\mathrm{O}$ point of the apexcardiogram.

Aortic valve closure indicates the onset of diastole though relaxation has already started at this point.
Once the aortic valve has closed there is a rapid fall of left ventricular pressure until the $O$ point of the apexcardiogram (Fig. 1) This interval is the rapid relaxation period and when it is prolonged (as often happens in hypertrophic cardiomyopathy) it reflects a reduced rate of fall of left ventricular pressure.

During this period when there is a gradient crossover between the left atrium and left ventricle, the mitral valve opens. This period from $A_{2}$ to $M o$ is the isovolumic relaxation period and it depends not only on the rate of fall of left ventricular pressure but also on the left atrial pressure at the time of gradient crossover between left ventricle and left atrium.

When the mitral valve opens, filling of the left ventricle starts and from this moment onwards the left ventricular pressure is the result of two major interdependent factors: the rate of relaxation and the rate of filling. 


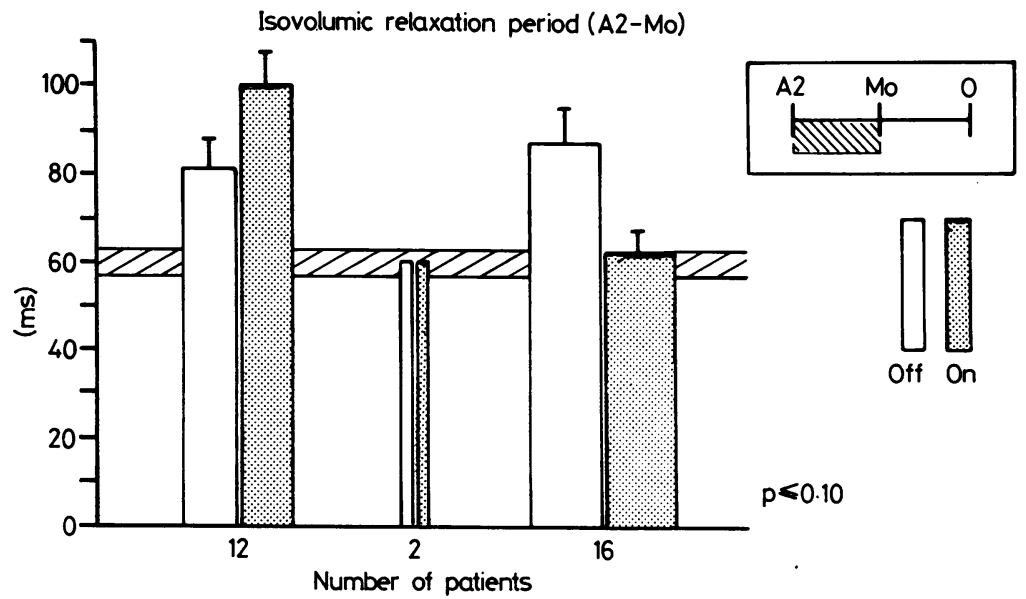

Fig. 4 Histograms showing the effect of beta blockade on isovolumic relaxation period (mean $\pm S D$ ) off treatment and on treatment (white and stippled histograms, respectively). The horizontal bar represents the normal mean value $\pm S D$ in normal subjects off beta blockade.

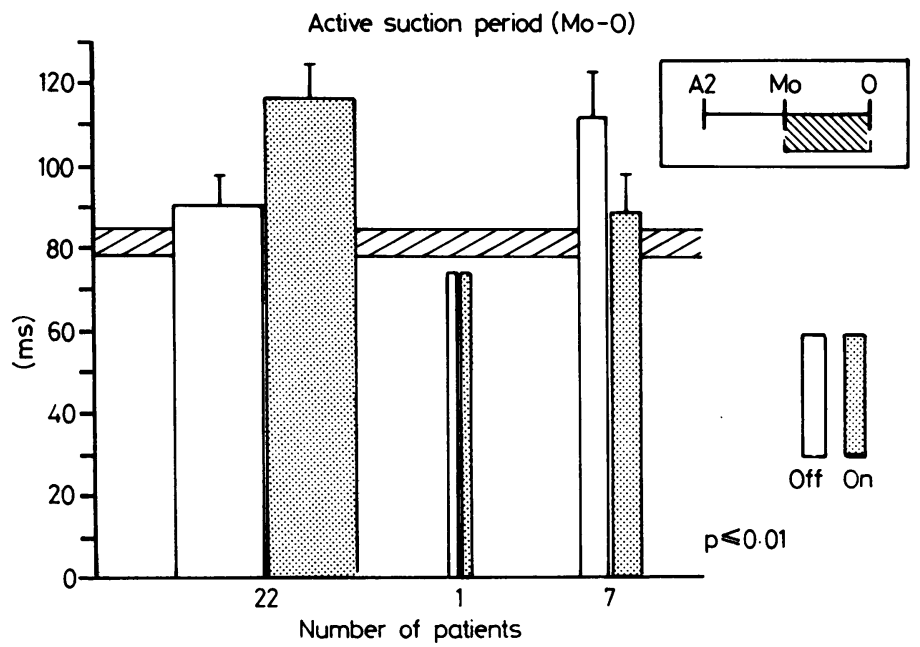

Fig. 5 Histograms showing the effect of beta blockade on active suction period (mean $\pm S D$ ) off treatment (white histograms) and on treatment (stippled histograms). The horizontal bar represents again the normal mean value $\pm S D$ in normal subjects off beta adrenergic blocking drugs.

From the mitral valve opening to the $O$ point of the apexcardiogram when the pressure continues to drop (Fig. 1) the rate of relaxation of the left ventricle is greater than the rate of blood filling the left ventricular cavity as a result of which there is a "sucking" effect of the blood coming from the left atrium to the left ventricle. This is the active suction period when most of the left ventricular filling occurs, ${ }^{21}$ which goes with a considerable increase in dimension during downstroke of the apexcardiogram ${ }^{2122}$ and rapid thinning of the posterior wall and interventricular septum. Therefore the longer this period is the better will be the left ventricular filling.

There is controversy about this period especially between those who believe that the relaxation and filling are purely passive processes, determined by venous pressure (vis-a-tergo of Harvey) and those who believe (as this study suggests) that diastolic filling is governed, at least in part, by an active process originating in the ventricular myocardium. This is 
shown by the fact that the mitral valve opens before minimum ventricular pressure is reached, so that early diastolic filling is associated with a reduction, rather than an increase, in left ventricular pressure. $\mathrm{Katz}^{23}$ concluded that it reflects a sucking effect of the left ventricle drawing blood into its chamber, and more recently ${ }^{24-26}$ further evidence has been produced for such diastolic suction. Hammermeister and Warbasse ${ }^{27}$ have shown that during this period (Mo-O), more than $50 \%$ of filling is already completed. Thus this period is really the "rapid filling wave" which is not the interval from $O$ to $F$ point of the apexcardiogram as was previously described; it was thought in the pre-echocardiographic era that the $\mathrm{O}$ point was coincident with mitral valve opening, since in many cases it corresponded with the opening snap in patients with mitral stenosis. ${ }^{28}$

From the $O$ point to the $F$ point of the apexcardiogram the rate of filling is greater than the rate of relaxation and this is why the left ventricular pressure starts to rise (Fig. 1) though in absolute terms the volume of blood coming to the left ventricle is less than during the active suction period. The interval from mitral valve opening until the $F$ point of the apexcardiogram is defined as the rapid filling period. Thus the $O$ point of the apexcardiogram is the "turning point" where the rate of filling and the rate of relaxation are in equilibrium.

The results of the present work using these techniques suggest that there was no significant prolongation of the rapid relaxation period (Fig. 3) or significant shortening of the isovolumic relaxation period (Fig. 4) after beta blockade. There was, how- ever, a significant increase in the interval from mitral valve opening to the $O$ point of the apexcardiogram as shown in Fig. 5 when most of the left ventricular filling occurs. Prolongation of this period occurred in 22 patients $(74 \%)$ but it remained the same or was shortened in one $(3 \%)$ and in seven $(23 \%)$, respectively. Thus beta blockade is usually valuable in hypertrophic cardiomyopathy since increase in left ventricular filling is achieved at a much lower pressure and this may explain the relief of symptoms. In addition because of this improved early filling, there is less distension of the left atrium, thus possibly preventing the occurrence of atrial fibrillation. The atrial beat also tends to be less powerful after beta blockade.

Shortening of the isovolumic relaxation period possibly contributes to the increase of the Mo-O interval. The former had a variable response after beta blockade, but showed an overall shortening which was not significant. Of 22 patients who had an increased active suction period, 11 had a shortened isovolumic relaxation period. In the remaining 11 it was prolonged or remained unchanged. In addition the increase of active suction period was not directly proportional to the shortening of the isovolumic relaxation period in the 11 patients where this period was shortened after treatment.

Thus, possibly the main reason for prolongation of the Mo-O interval is that the equilibrium point ( $O$ point) is reached much later because of relaxation at a much lower pressure as a consequence of which there is increased filling in early diastole. These results confirm the work of de la Calzada et al. ${ }^{15}$ who have shown acceleration of diastolic closure rate of the

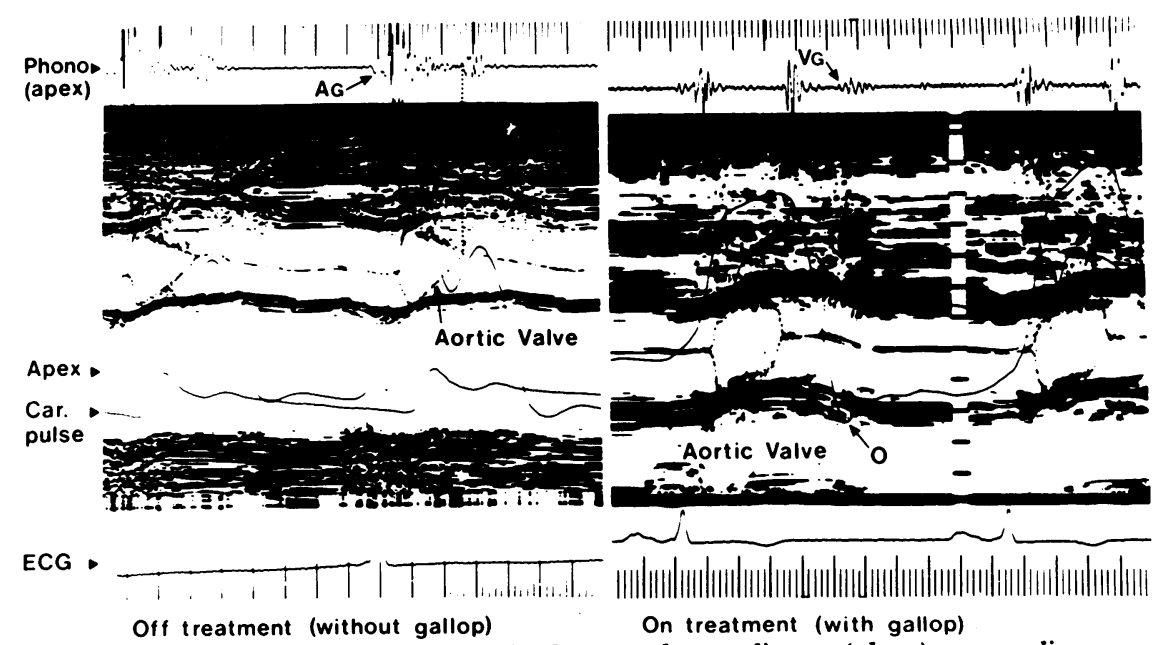

Fig. 6 Aortic valve echocardiogram with simultaneous phonocardiogram (phono), apexcardiogram (apex), carotid pulse, and electrocardiogram off and on treatment. Off treatment, as a result of low stroke volume, the aortic leaflets begin to close early while on treatment the leaflets remain widely open throughout systole. 


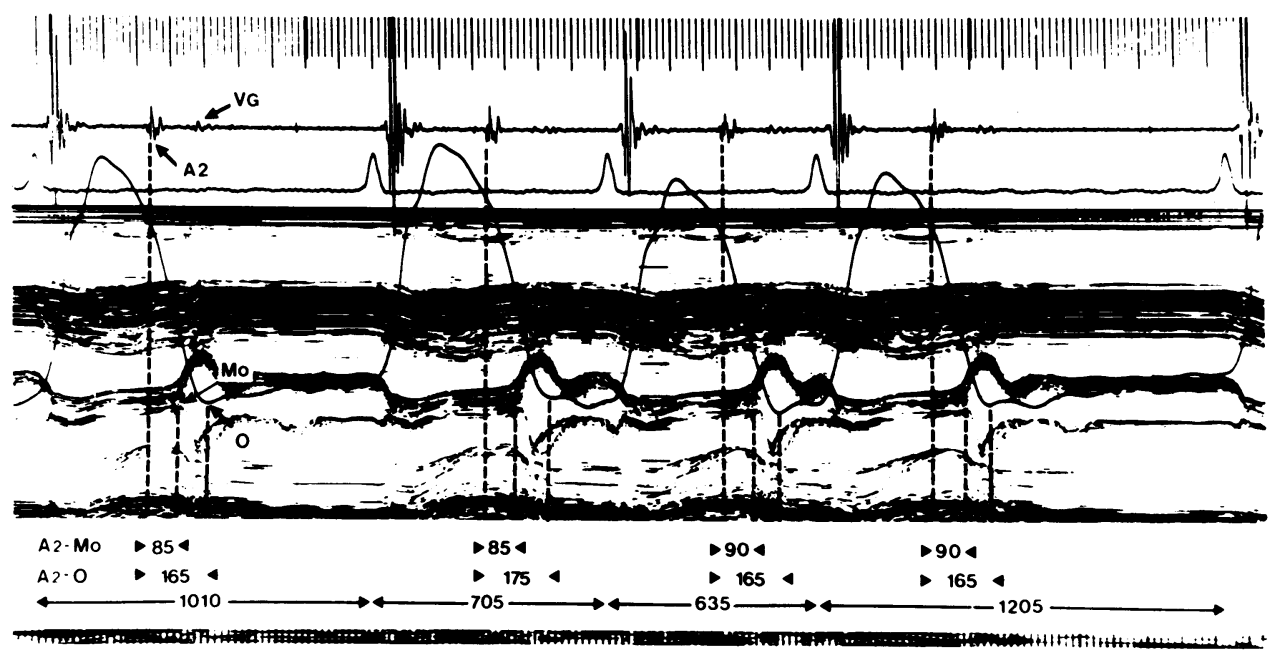

Fig. 7 Patient with hypertrophic cardiomyopathy in atrial fibrillation. The isovolumic relaxation period $\left(A_{2}-M o\right)$ and the rapid relaxation period $\left(A_{2}-O\right)$ almost remain constant with different $R R$ intervals.

mitral valve after beta blockade probably related to increased ventricular filling.

The consequence of this increased filling can be seen in Fig. 6 where after treatment there was an increase in stroke volume, as shown by increased aortic valve opening.

This increase in the active suction period was not affected by age, by sex, by the type or amount of the drug, by blood pressure, or by heart rate. This can be seen in Fig. 7 where a patient with hypertrophic cardiomyopathy and in atrial fibrillation with different $R R$ intervals had almost constant rapid relaxation period and isovolumic relaxation period. In this group of 30 patients the coefficient of correlation between the heart rate and the diastolic time intervals in early diastole $\left(\mathrm{A}_{2}-\mathrm{O}, \mathrm{A}_{2}-\mathrm{Mo}, \mathrm{Mo}-\mathrm{O}\right)$ was extremely low. Nor was this increase of active suction period affected by the presence of a gradient to the outflow tract of the left ventricle.

The effect of beta blockade in lowering the heart rate should not be underestimated because an appreciable amount of filling occurs during the slow relaxation period, diastasis, and the atrial component of diastole which are all related closely to the heart rate. Indeed, clinically there is pronounced deterioration of these patients when they are in atrial fibrillation.

Dr R F Alvares acknowledges his fellowship from the Calouste Gulbenkian Foundation (Lisbon).

\section{References}

1 Goodwin JF. Treatment of the cardiomyopathies. $A m \mathcal{F}$ Cardiol 1973; 32: 341-51.
2 Frank MJ, Abdulla AM, Canedo MI, Saylors RE. Long-term medical management of hypertrophic obstructive cardiomyopathy. Am f Cardiol 1978; 42: 9931001.

3 Shah PM. Newer concepts in hypertrophic obstructive cardiomyopathy-Part II. FAMA 1979; 242: 1771-6.

4 Hubner PJB, Ziady GM, Lane GK, et al. Double-blind trial of propranolol and practolol in hypertrophic cardiomyopathy. Br Heart $\mathcal{F}$ 1973; 35: 1116-23.

5 Swan DA, Bell B, Oakley CM, Goodwin JF. Analysis of symptomatic course and prognosis and treatment of hypertrophic obstructive cardiomyopathy. Br Heart $\mathcal{f}$ 1971; 33: 671-85.

6 Hardarson T, de la Calzada CS, Curiel R, Goodwin JF. Prognosis and mortality of hypertrophic obstructive cardiomyopathy. Lancet 1973; ii: 1462-7.

7 Goodwin JF. Congestive and hypertrophic cardiomyopathies. A decade of study. Lancet 1970; i: 731-9.

8 Goodwin JF, Oakley CM. The cardiomyopathies. $\mathrm{Br}$ Heart $\mathcal{F}$ 1972; 34: 545-52.

9 Goodwin JF. Prospects and predictions for the cardiomyopathies. Circulation 1974; 50: 210-9.

10 Braunwald E, Ebert PA. Hemodynamic alterations in idiopathic hypertrophic subaortic stenosis induced by sympathomimetic drugs. Am f Cardiol 1962; 10: 489-95.

11 Epstein SE, Braunwald E. Beta-adrenergic receptor blocking drugs. Mechanisms of action and clinical applications. N Engl f Med 1966; 275: 1106-12.

12 Brockenbrough EC, Braunwald E, Morrow AG. A hemodynamic technic for the detection of hypertrophic subaortic stenosis. Circulation 1961; 23: 189-94.

13 Webb-Peploe MM. Management of hypertrophic obstructive cardiomyopathy by beta-blockade. In: Wolstenholme GEW, O'Connor M, eds. Ciba Foundation study group No. 37. London: Churchill, 1971: 103-11.

14 Webb-Peploe MM, Croxson RS, Oakley CM, Goodwin JF. Cardioselective beta-adrenergic blockade in hypertrophic obstructive cardiomyopathy. Postgrad Med $\mathcal{F}$ 
1977; 47, suppl: 93-7.

15 de la Calzada CS, Ziady GM, Hardarson T, Curiel R, Goodwin JF. Effect of acute administration of propranolol on ventricular function in hypertrophic obstructive cardiomyopathy measured by non-invasive techniques. Br Heart f 1976; 38: 798-803.

16 Alvares RF. Diastolic function and prognosis in hypertrophic cardiomyopathy. University of London: $\mathrm{Ph} . \mathrm{D}$ thesis 1980 .

17 Hollister RM, Goodwin JF. The electrocardiogram in cardiomyopathy. Br Heart $\mathcal{f}$ 1963; 25: 357-74.

18 Popp RL, Harrison DC. Ultrasound in the diagnosis and evaluation of therapy of idiopathic hypertrophic subaortic stenosis. Circulation 1969; 40: 905-14.

19 Shah PM, Gramiak R, Adelman AG, Wigle ED. Role of echocardiography in diagnostic and hemodynamic assessment of hypertrophic subaortic stenosis. Circulation 1971; 44: 891-8.

20 Willems JLH, Denef B, Kesteloot H, De Geest H. Comparability and reproducibility of apex cardiogram recorded with six different transducer systems. $\mathrm{Br}$ Heart f 1979; 41: 716-26.

21 Gibson DG, Brown D. Measurement of instantaneous left ventricular dimension and filling rate in man, using echocardiography. Br Heart f 1973; 35: 1141-9.

22 Sanderson JE, Traill TA, St. John Sutton MG, Brown DJ, Gibson DG, Goodwin JF. Left ventricular relaxation and filling in hypertrophic cardiomyopathy-an echocardiographic study. Br Heart $\mathcal{F}$ 1978; 40: 596-601.

$23 \mathrm{Katz} \mathrm{LN}$. The role played by the ventricular relaxation process in the filling ventricle. Am $\mathcal{F}$ Physiol 1930; 95: 542-53.

24 Porter CM, Baxley WA, Eddleman EE, Frimer M, Rackley CE. Left ventricular dimensions and dynamics of filling in patients with gallop heart sounds. Am $\mathcal{F} \mathrm{Med}$ 1971; 50: 721-7.

25 Horwitz LD, Bishop VS. Left ventricular pressuredimension relationships in the conscious dog. Cardiovasc Res 1972; 6: 163-71.

26 Sabbah HN, Anbe DT, Stein PD. Negative intraventricular diastolic pressure in patients with mitral stenosis: evidence of left ventricular diastolic suction. Am $₹$ Cardiol 1980; 45: 562-6.

27 Hammermeister KE, Warbasse JR. The rate of change of left ventricular volume in man. 2. Diastolic events in health and disease. Circulation 1974; 49: 739-47.

28 Benchimol A, Dimond EG, Carson JC. The value of the apexcardiogram as a reference tracing in phonocardiography. Am Heart f 1961; 61: 485-93.

Requests for reprints to Dr R F Alvares, Largo Pedro Correia Marques, No. 2-8 Esquerdo, Lisbon 1500, Portugal. 